\title{
DECARBONIZATION OF THE TRANSPORT INDUSTRY, PROS AND CONS
}

\author{
Irina Muravyova ${ }^{1}$ \\ Yanina Maryanko ${ }^{2}$
}

DOI: https://doi.org/10.30525/978-9934-26-076-6-2

The European Commission has published a new hydrogen strategy [1], the goal of which is to develop hydrogen technology to maximize $\mathrm{CO}_{2}$ emissions by 2050. This strategy coincides in the IRU's perspective as for transport decarbonizing. But the organization says the transition has to be gradual and elaborate so the measures taken do not harm the transport industry. The use of hydrogen technologies opens up the opportunities for both the world and Ukraine for decarbonization of the main branches of the Economy, as well as for building a new industry and creating additional employment.

\footnotetext{
${ }^{1}$ Odesa State Academy of Civil Engineering and Architecture, Ukraine

${ }^{2}$ Odesa State Academy of Civil Engineering and Architecture, Ukraine
} 
In the commercial transport sector, «green» hydrogen is the most perspective alternative fuel: one kilogram of hydrogen contains 3 times more energy (as we can see in the diagram) than its oil equivalent, and 330 times more energy than one kWh battery cell. This type of hydrogen is called «green» because it is produced from renewable sources such as biogas and water [2].

New technologies are expensive, and the most commercial road transport operators in the EU are small and medium-sized enterprises, to achieve strategy's goals the companies will need financial incentives to invest in more eco-friendly mechanical-transport parks.

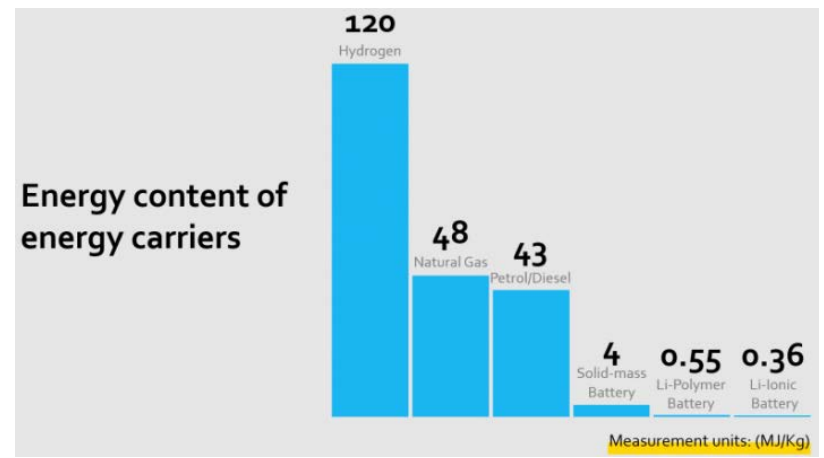

Given the ambitious of decarbonisation plans, the main task now is to make Purified hydrogen lucrative to transport operators: to ensure the availability of the technology, its economic and operational viability. This will help to gradually reduce $\mathrm{CO}_{2}$ emissions without harming the transport industry, but whether this is the case.

Simulations show that measuring $\mathrm{CO}_{2}$ emissions only at the commercial vehicle level in some regions can double the actual emissions [3]. Heavy commercial transport, including buses and trucks, are responsible for only 950 million tonnes of $\mathrm{CO}_{2}$ in annual exhaust emissions, or $2.5 \%$ of global emissions when assessed on a «tank-to-wheel» basis.

Hydrogen and electricity are often mistakenly considered zero-emission fuel. Taking into account all $\mathrm{CO}_{2}$ emissions, including «tank-to-wheel» ones, more realistic picture of the carbonic trace of these alternative fuels can be provided. Only in Europe, the United States and China, this approach to the assessment, especially given the current energy consumption pattern, shows that when using electricity and hydrogen as the fuel, $\mathrm{CO}_{2}$ emissions increase by $45 \%$ and $72 \%$, respectively, compared to the traditional diesel fuel. Thus, when converting heavy vehicles to electricity and hydrogen without using low 
and carbon-free energy sources, 400 to 700 million tons of annual $\mathrm{CO}_{2}$ emissions will not be taken into account.

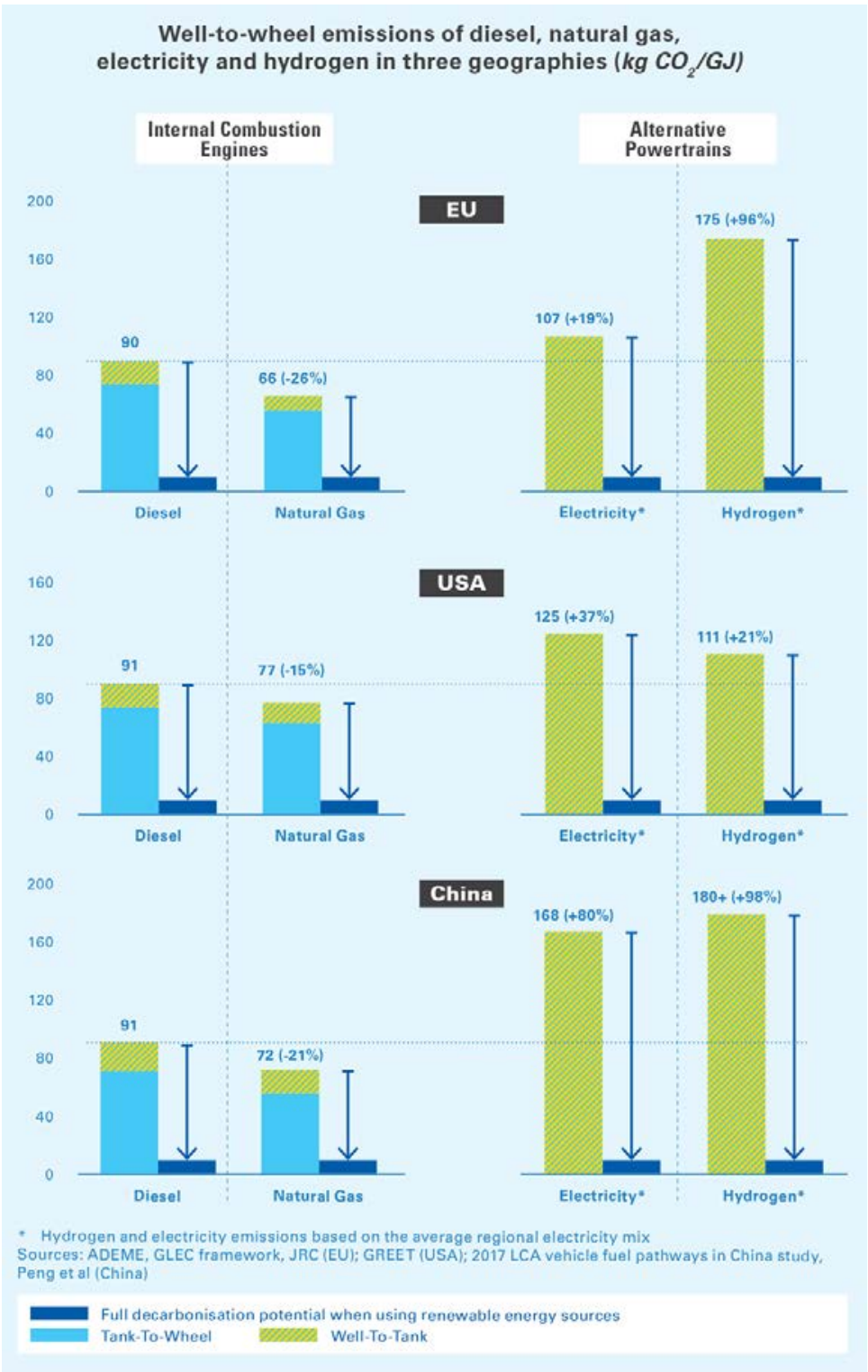


The decarbonization of commercial road transport is not only a large-scale task but also an expensive one. The right mix of stimulus and investment that will accelerate the transition to low-carbon and carbon-free types of fuel to meet the 2030 and 2050 targets can only be achieved if $\mathrm{CO}_{2}$ emissions are properly accounted for. A nonobjective «tank-to-wheel» approach that measures emissions in the exhaust gases instead of a comprehensive estimate of the total emissions from «tank-to-wheel» stages will not provide an effective policy to reduce $\mathrm{CO}_{2}$ emissions from commercial road transport. Road transport operators need clearness, not unworkable, solutions. Only in this way they will be able to continue working on such a difficult task as the effective decarbonization of the transport park and traffic.

\section{References:}

1. Powering a climate-neutral economy: Commission sets out plans for the energy system of the future and clean hydrogen. URL: https://ec.europa.eu/commission/ presscorner/detail/en/ip_20_1259

2. Decarbonization without prejudice to carriers. URL: https://logist.today/ dnevnik_logista/2020-07-17/dekarbonizacija-bez-ushherba-dlja-perevozchikov-v-iruprokommentirovali-novuju-vodorodnuju-strategiju-es/

3. Decarbonising road transport, URL: https://www.iru.org/resources/irulibrary/decarbonising-road-transport?token=21708298306a671fd57f166b17d261eb1619775826-753dc7cf 